\title{
On G.P.P-Rings
}

\author{
Manal.A. Abd \\ University of Mosul \\ College of Comp. and Math Science \\ Dept. of Mathematics \\ Mosul, Iraq
}

Received

2006/7/17
Accepted

$2006 / 4 / 26$

$$
\begin{aligned}
& \text { الخلاصة : } \\
& \text { في هذا البحث ندرس الحلقات من النمط - P.P الهعدة. لقد بر هنا أن الحلقات من }
\end{aligned}
$$

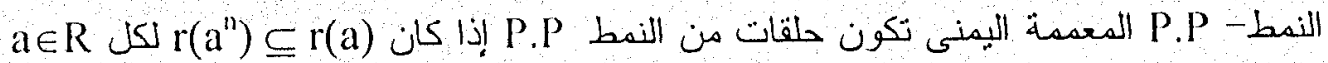

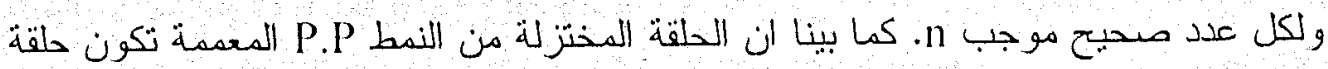

$$
\begin{aligned}
& \text { منتظمة قوية من النمط - } \pi \text { ، أذا كان كل عنصر ليس من قو اسم الصفر لـ معكوس . }
\end{aligned}
$$

\section{Abstract:}

In this work we introduce the notion of G.P.P - rings and some of it is basic properties, we prove that if $R$ is a right G.P.P - ring, then $R$ is P.P- ring if $r\left(a^{n}\right) \subseteq r(a)$ for every $a \in R$ and a positive integer $n$. We also consider that a reduced G.P.P - Ring with every non - zero divisor has inverse is strongly $\pi$-Regular .

\section{1- Introduction :}

Throughout this paper, $\mathrm{R}$ will denote an associative ring with identity, and all modules are unitary R-module. Recall that ; 1) $R$ is called reduced if $R$ has non-zero nilpotent elements [5]. 2) $R$ is right (left) duo if every right(left) ideal of $R$ is an ideal of $R$. 3) $R$ is strongly 
$\pi$-regular if for every $a \in R$, There exists $b \in R$ and a positive integer $n$ such that $\left.\mathrm{a}=\mathrm{a}^{2 \mathrm{n}} \mathrm{b}[4] ; 4\right) \cdot \mathrm{A}$ right $\mathrm{R}$-module $\mathrm{M}$ is called general right principally injective (briefly right $\mathrm{GP}$-injective) if for any $0 \neq a \in R$ there exist a positive integer $n$, such that $\mathrm{a}^{\mathrm{n}} \neq 0$. and any right $\mathrm{R}$-homomorphism of a $R$ into $M$ extends to one of $R$ into $M .5$ ) for any element a in $R$ we define a right annihilator of $a$ by $r(a)=\{x \in R: a x=0\}$ and left annihilator of $\mathrm{a}, \mathrm{I}(\mathrm{a})$ is similarly defined.

\section{2-Basic Properties:}

In this section we introduce the notion of G.P.P - rings, we give some of it is basic properties. Following [2] A ring $R$ is said to be right (left) P.P - ring if for every $a \in R$, there exist $b \in R$ such that $a=a b$ and $r(a)=r(b)(a=b a, l(a)=l(b))$.

\section{Definition 2-1:}

A ring $R$ is siad to be right G.P.P - ring if for every $a \in R$ there exist $\mathrm{e} \in \mathrm{R}$ and a positive integer $\mathrm{n}$ such that $\mathrm{a}^{n}=\mathrm{a}^{\mathrm{n}} \mathrm{e}$ and $\mathrm{r}\left(\mathrm{a}^{\prime \prime}\right)=r(\mathrm{e})$.

Clearly every P.P - ring is an G P.P - ring, however The converse is not true. we now consider a necessary and sufficent condition for G P.P-ring to be an P.P-ring.

\section{Lemma 2-2:-} P.P - ring.

Let $R$ be a right GP.P. ring and $r\left(a^{\prime \prime}\right) \subseteq r(a)$ for every $a \in R$ then $R$ is

Proof: Assume that $R$ is GP.P. ring, then $a^{n}=a^{n} e$ and $r\left(a^{n}\right)=r(e)$. Implies that $\mathrm{a}^{\mathrm{n}}(1-\mathrm{e})=0$, and hence $1-\mathrm{e} \in \mathrm{r}\left(\mathrm{a}^{\mathrm{n}}\right) \subseteq \mathrm{r}(\mathrm{a})$.

There fore $(1-e) \in r(a)$ where $a=a e$. and $r(e)=r\left(a^{n}\right) \subseteq r(a)$ Thus $a=a e$ and $r(a)=r(e)$.

\section{Throrem 2-3:-}

$R$ is G.P.P-ring if and only if for all $a \in R, r\left(a^{n}\right)$ is direct summand.

\section{Proof :-}

Assum that $r\left(a^{n}\right)$ is direct summand, then there exists a right ideal I such that $r\left(a^{n}\right)+I=R$. In particular, $d+b=1$, for some $d \in r\left(a^{n}\right)$ and $\mathrm{b} \in \mathrm{I} \quad a^{n} \cdot 1=a^{n}(d+b)=a^{n} d+a^{n} b=0+a^{n} b=a^{n} b$ Implies that $\mathrm{a}^{n} \mathrm{~b}=\mathrm{a}^{\mathrm{n}}$. Now, we must prove that $r\left(a^{n}\right)=r(b)$. Let $x \in r(b)$, then $b x=0$, and 
$a^{n} b x=0$. So $a^{n} x=0$ and $x \in r\left(a^{n}\right)$.

Hence $r(b) \subseteq r\left(b^{n}\right)$ Now Let $y \in r\left(a^{n}\right)$, then $a^{n} y=0$ and $a^{n} b y=0$.

Thus by $\in r\left(a^{n}\right)$. but by $\in I$ implies that by $\in r\left(a^{n}\right) \cap I=0$, then $y \in r(b)$ and $r\left(a^{n}\right) \subseteq r(b)$. Therefore $r\left(a^{n}\right)=r(b)$.

\section{Conversely:}

Assume that $R$ is right G. P.P - ring, then for every $a \in R$ there exists $b \in R$ and a positive integer $n$ such that $a^{n}=a^{n} b$ and $r\left(a^{n}\right)=r(b)$, Since $a^{n}(1-b)=0$, then $(1-b) \in r\left(a^{n}\right)$. So $1=b+(1-b)$, hence $R=b R+r\left(a^{n}\right)$. Let $x \in b R \cap r\left(a^{n}\right)$ implies that $x=b y$ for some $y \in R$ and $a^{n} x=0$, so $a^{n} b y=0=a^{n} y$. Hence $y \in r\left(a^{n}\right)=r(b)$ and $b y=0=x$. Thus $b R \cap r\left(a^{n}\right)=0$. Therefore $r\left(a^{n}\right)$ is directed summand.

\section{Lemma 2-4:[3]}

If $R$ is a duo ring, then every idempotent element in $R$ is central.

\section{Theorem 2.5:}

Let $R$ be a duo G.P.P - ring and let $J_{1}, J_{2}$ be ideals in R. Then $r\left(J_{1}\right)+r\left(J_{2}\right)$ generated by a central idempotent element.

Proof: Let $R$ be a duo G.P.P - ring and let $J_{1}, J_{2}$ be two ideals in R. Then $r\left(J_{1}\right)=e_{1} R$ and $r\left(J_{2}\right)=e_{2} R$ where $e_{1}, e_{2}$ are idempotent elements. Since $R$ is duo ring then by Lemma $2-4 e_{1}, e_{2}$ are central idempotents. Also $r\left(J_{1}\right)+r\left(J_{2}\right)=e_{1} R+e_{2} R=e_{1} R+e_{2} e_{1} R+e_{2}\left(l-e_{1}\right) R$. And $e_{1} R+e_{2} R \subseteq e_{1} R+e_{2}\left(1-e_{1}\right) R \subset e_{1} R+e_{2} R=e_{1} R+e_{2}\left(1-e_{1}\right) R$, so $r\left(J_{1}\right)+r\left(J_{2}\right)=e_{1} R+e_{2}\left(1-e_{1}\right) R$.

Let $e_{3}=e_{2}\left(1-e_{1}\right)$, we prove that $e_{3}$ is idempotent element

$$
\begin{aligned}
e_{3}^{2} & =\mathrm{e}_{2}\left(1-\mathrm{e}_{1}\right) \mathrm{e}_{2}\left(1-\mathrm{e}_{1}\right) \\
& =\left(\mathrm{e}_{2}-\mathrm{e}_{2} \mathrm{e}_{1}\right)\left(\mathrm{e}_{2}-\mathrm{e}_{2} \mathrm{e}_{1}\right) \\
& =e_{2}^{2}-e_{2}^{2} e_{1}-e_{2} e_{1} e_{2}+e_{2} e_{1} e_{2} e_{1} \\
& =e_{2}^{2}-e_{2}^{2} e_{1}-e_{2}^{2} e_{1}+e_{2}^{2} e_{1}^{2} \\
& =\mathrm{e}_{2}-\mathrm{e}_{2} \mathrm{e}_{1} \text { (since } \mathrm{e}_{1}, \mathrm{e}_{2} \text { are idempotent elements) } \\
& =\mathrm{e}_{2}\left(1-\mathrm{e}_{1}\right) \\
& =\mathrm{e}_{3}
\end{aligned}
$$

Hence $e_{3}$ is idempotent element. Since $\mathrm{R}$ is duo ring, then by Lemma $2-4, e_{3}$ is central idempotent element.

Now $e_{1} e_{3}=e_{1}\left(e_{2}\left(1-e_{1}\right)\right)$.

Similariy $e_{3} e_{1}=0$.

$$
=e_{1} e_{2}\left(1-e_{1}\right)=e_{1} e_{2}-e_{1} e_{2} e_{1}=e_{1} e_{2}-e_{1} e_{2}=0 \text { (since } e_{1} \text { is idempotent) }
$$

Now let $x \in\left(e_{1}+e_{3}\right) R$ then $x=\left(e_{1+} e_{3}\right) r ; r \in R$ 
Thus $\mathrm{x}=\mathrm{e}_{1} \mathrm{r}+\mathrm{e}_{3} \mathrm{r} \in \mathrm{e}_{1} \mathrm{R}+\mathrm{e}_{3} \mathrm{R}$ and $\left(\mathrm{e}_{1}+\mathrm{e}_{3}\right) \mathrm{R} \subseteq \mathrm{e}_{1} \mathrm{R}+\mathrm{e}_{3} \mathrm{R}$

Also let $y \in e_{1} R+e_{3} R$. Then $y=e_{1} r_{1}+e_{3} r_{3}$ for some $r_{1}, r_{3} \in R$

$\left(e_{1}+e_{3}\right) y=\left(e_{1}+e_{3}\right)\left(e_{1} r_{1}+e_{3} r_{3}\right)$

$$
\begin{aligned}
& =e_{1}^{2} r_{1}+e_{1} e_{3} r_{3}+e_{3} e_{1} r_{1}+e_{3} e_{3} r_{3} \\
& =e_{1} r_{1}+0+0+e_{3} r_{3} \\
& =e_{1} r_{1}+e_{3} r_{3}=y \text { implies y } \in\left(e_{1}+e_{3}\right) R
\end{aligned}
$$

Thus $\mathrm{e}_{1} \mathrm{R}+\mathrm{e}_{3} \mathrm{R}=\left(\mathrm{e}_{1}+\mathrm{e}_{3}\right) \mathrm{R}$

That is $r\left(J_{1}\right)+r\left(J_{2}\right)=\left(e_{1}+e_{3}\right) R$, when $\left(e_{1}+e_{3}\right)$ is central idempotent element.

\section{3-The connection between G. P.P. - Rings and other rings:}

\section{Theorem 3-1:-}

Let $\mathrm{R}$ be a reduced G P.P. - ring with every non-zero divisor has inverse. Then $\mathrm{R}$ is strongly $\pi$ - Regular.

Proof: we must prove $a^{n} R \cap$ e $R=0$ for all $a \in R$. Since $R$ is G. P.P. ring, then $r\left(a^{\prime \prime}\right)=r(e)$ where $e$ is central idempotent element. Let $x \in a^{n} R$ $\cap$ e R implies that $x=a^{n} r$, and $x=e r$ for some $r, r^{\prime} \in R$.

Now, See that $x=e r^{\prime}=$ e. e $r^{\prime}=$ e x. Since $e \in c R=r\left(a^{n}\right)$ then $a^{n} e=e a^{\prime \prime}$ $=0$. Also e $x=e a^{n} r=0, x=a^{\prime \prime} r$, then $x=e x=0$. Thus $a^{n} R$ ne $R=0$.

Now we must prove that $\left(a^{\prime \prime}+e\right)$ is non-zero divisor.

Let $\left(a^{\prime \prime}+e\right) y=0$ Implies that $a^{n} y=-e y$. That is $a^{n} y=-e y \in a^{\prime \prime} R \cap e R$.

Since $a^{\prime \prime} R \cap R=0$.

Then $a^{n} y=$ e $y=0$ and we have $a^{n} y=0$. That is $y \in r\left(a^{n}\right)=e R$.

There exists $r_{1} \in R$ such that $y=e r_{1}$, also $0=e y=e . e r_{1}=e^{2} r_{1}=e r_{1}=y$ (e is idempotent), since $\left(a^{n}+e\right)$ is a non-zero divisor.

Let $x$ be the inverse of $\left(a^{n}+e\right)$. Then we have $\left(a^{n}+e\right) x=1$. implies that $a^{n}\left(a^{n}+e\right) x=a^{n}$ implies $\left(a^{2 n}+a^{n} e\right) x=a^{n}$.

Since $a^{n} e=0$, then $a^{2 n} x=a^{n}$. Therefore $R$ is strongly $\pi$-regular ring.

\section{Theorem 3-2:}

Let $\mathrm{R}$ be a G.P.P.-ring with $\mathrm{r}\left(\mathrm{a}^{\mathrm{n}}\right) \subseteq \mathrm{r}(\mathrm{a})$ for any $\mathrm{a} \in \mathrm{R}$ and a positive integer $n$. Then $a^{n} R$ is idempotent ideal if $R / a^{n} R$ is GP-injective ring.

\section{Proof:}

Since $R$ be G.P.P.-ring, then for all $a \in R$ there exists $b \in R$ and $a$ positive integer $n$, such that $a^{n}=a^{n} b$ and $r\left(a^{n}\right)=r(b)$.

Now define a right $R$-homomorphism $f: a^{n} R \rightarrow R / a^{n} R$ by $f\left(a^{n} x\right)=b x$ $+a^{n} R$ for all $x \in R$. Then, $f$ is well-defined, indeed, let $a^{n} x_{1}=a^{n} x_{2}$ for any two elements $x_{1}, x_{2}$ in $R$, then $a^{n} x_{1}-a^{n} x_{2}=0$. So $a^{n}\left(x_{1}-x_{2}\right)=0$. 
Thus $\left(x_{1}-x_{2}\right) \in r\left(a^{n}\right)=r(b)$ then $x_{1}-x_{2} \in r(b)$ implies $b\left(x_{1}-x_{2}\right)=0$.

Hence $b x_{1}=b x_{2}$ therefore $f\left(a^{n} x_{1}\right)=b x_{1}+a^{n} R=b x_{2}+a^{n} R=f\left(a^{n} x_{2}\right)$

Now define $g: R / a^{n} R \rightarrow R /\left(a^{n} R\right)^{2}$ by $g\left(y+a^{n} R\right)=a^{n} y+\left(a^{n} R\right)^{2}$ for all $y \in R$ and by the same way we can prove that $g$ is well-defined. Since $R / a^{n} R$ is

GP- injective ring, there exists $c \in R$ Such that

$f\left(a^{n} x\right)=\left(c+a^{n} R\right) a^{n} x=c a^{n} x+a^{n} R$.

Now

$$
\begin{aligned}
g\left(f\left(a^{n} x\right)\right) & =g\left(b x+a^{n} R\right) \\
& =g\left(c a^{n} x+a^{n} R\right) \\
& =a^{n} c a^{n} x+\left(a^{n} R\right)^{2} \\
& =a^{n} x+\left(a^{n} R\right)^{2}
\end{aligned}
$$

So $a^{n} x+\left(a^{n} R\right)^{2}=a c a^{n} x+\left(a^{n} R\right)^{2}$.

But $a^{n} x \in a^{n} R$, then $\left(a^{n} R\right)^{2} \subseteq a^{n} R$. Thus $a^{n} x+\left(a^{n} R\right)^{2} \in a^{n} R$ and $a^{n} c a^{n} x \in a^{n} R a^{n} R=\left(a^{n} R\right)^{2}$. This gives $a^{n} c a^{n} x+\left(a^{n} R\right)^{2} \in\left(a^{n} R\right)^{2}$. Hence $a^{n} R \subseteq\left(a^{n} R\right)^{2}$. Therefore $a^{n} R=\left(a^{n} R\right)^{2}$

\section{References :}

[1] Ahmed H.S. (1974), " On Commutative P.P-Rings", M.Sc - Thesis, Baghdad University, Iraq.

[2] Endo S. ( 1960), Note on P.P - Rings, Pac.J. Math. (3) 41. P 687-693.

[3] Mohammad M.R. (1996), "On $\pi$ - Regular Rings", M.Sc. Thesis , university of Mosul ,Iraq.

[4] Yue Chi Ming R. (1976), On annihilator ideals, Math. J. Okayama University, (19), p. 51-53.

[5] Yue Chi Ming R. (1996), On P-injectivity and generalization, Riv. Mat. University Parma. (5), p. 183-188. 